\title{
PELUANG DAN TANTANGAN PEKERJA MIGRAN INDONESIA DALAM MASYARAKAT EKONOMI ASEAN ${ }^{1}$
}

\author{
Achmad Zulfikar \\ Magister Ilmu Politik Universitas Hasanuddin \& \\ Pendiri Asosiasi Peneliti dan Pemerhati Pekerja Migran Indonesia \\ Email: apa@kabarfikar.com
}

\begin{abstract}
The ASEAN Community has come into force on 31 December 2015 with three pillars i.e. ASEAN Economic Community, ASEAN Political and Security Community and ASEAN Socio-Cultural Community. Indonesian migrant workers (IMW) have tremendous potential to develop. Statistics of the National Agency for the Placement and Protection of Indonesian Workers (BNP2TKI) shows the placement of IMW in 2011 with 586.802 people, 494.609 people (2012), 512.168 persons (2013), 429.872 people (2014) and 275.736 people in 2015. Statistics shows a significant number of migrant workers abroad. Interesting facts of Indonesia's migration for works in Southeast Asia, Malaysia became the country with the largest number of placements. Followed by Singapore, Brunei Darussalam and Thailand. These four ASEAN member countries are located among 25 countries placement of IMW from the distribution of 170 countries. Convergence theory became the theoretical framework used in this study. The method used is literature study to trace the sources of information relevant to this study. This study concludes that IMW has the opportunity to access employment which has been agreed upon by ASEAN member countries through Mutual Recognition Agreements (MRA), however the profession agreed by MRAs still needs support for its development from the Indonesian government in order to be optimally utilized. While the challenge faced is the profile of IMW is still dominated by informal workers, so it takes the Indonesian government efforts to increase interest as a formal workforce.
\end{abstract}

Keywords: Indonesian Migrant Workers, ASEAN Economic Community, Southeast Asian

\begin{abstract}
Abstrak
Masyarakat ASEAN telah mulai berlaku sejak 31 Desember 2015 dengan tiga pilar yakni Masyarakat Ekonomi ASEAN, Masyarakat Politik dan Keamanan ASEAN dan Masyarakat Sosial Budaya ASEAN. Pekerja migran Indonesia/tenaga kerja Indonesia (PMI/TKI) memiliki potensi yang luar biasa untuk dikembangkan. Statistik Badan Nasional Penempatan dan Perlindungan Tenaga Kerja Indonesia (BNP2TKI) menunjukkan penempatan PMI/TKI pada tahun 2011 sebanyak 586.802 orang, selanjutnya 494.609 orang (2012), 512.168 orang (2013), 429.872 orang (2014) dan 275.736 orang di tahun 2015. Statistik tersebut menunjukkan angka yang cukup signifikan. Fakta yang menarik dari migrasi pekerja Indonesia di kawasan Asia Tenggara yakni Malaysia menjadi negara penempatan dengan jumlah terbesar. Disusul Singapura, Brunei Darussalam dan Thailand. Keempat negara anggota ASEAN ini berada di antara 25 negara penempatan TKI/PMI dari sebaran 170 negara. Teori konvergensi menjadi kerangka teoretik yang digunakan dalam kajian ini. Metode yang digunakan yakni studi pustaka untuk menelusuri sumber-sumber informasi yang relevan dengan kajian ini. Kajian ini menyimpulkan bahwa TKI/PMI berpeluang untuk mengakses lapangan kerja yang telah disepakati bersama oleh negara anggota ASEAN melalui Mutual Recognition Agreements (MRA), namun demikian profesi yang telah disepakati MRAs masih membutuhkan dukungan untuk pengembangannya dari pemerintah Indonesia agar dapat dimanfaatkan secara optimal. Sedangkan tantangan yang dihadapi yakni profil TKI/PMI yang masih didominasi oleh tenaga kerja informal, sehingga diperlukan upaya pemerintah Indonesia untuk meningkatkan minat sebagai tenaga kerja formal.
\end{abstract}

Kata Kunci: Pekerja Migran Indonesia, Masyarakat Ekonomi ASEAN, Asia Tenggara

${ }_{1}^{1}$ Makalah telah dipresentasikan dalam Konvensi Nasional Asosiasi Ilmu Hubungan Internasional VII Tahun 2016 di Universitas Hasanuddin, Makassar, Indonesia pada 23-24 November 2016. 


\section{PENDAHULUAN}

The Association of Southeast Asian Nations (ASEAN), organisasi regional di kawasan Asia Tenggara yang didirikan 8 Agustus 1967 dalam dokumen pendiriannya, The ASEAN Declaration/The Bangkok Declaration menyebutkan bahwa maksud dan tujuan pertama didirikannya ASEAN adalah untuk mempercepat pembangunan ekonomi, kemajuan sosial, dan perkembangan kejayaan di kawasan guna memperkuat dasar bagi sebuah komunitas yang sejahtera dan damai di Asia Tenggara. Adapun maksud dan tujuan kedua untuk meningkatkan perdamaian dan stabilitas kawasan.

Dalam rangka mewujudkan tujuan ASEAN tersebut, sejak 31 Desember 2015 Indonesia bersama 9 negara anggota ASEAN lainnya yakni: Brunei Darussalam, Filipina, Malaysia, Singapura, Thailand, Vietnam, Laos, Myanmar dan Kamboja telah memasuki babak baru dalam kerangka ASEAN Community. Komunitas ini terdiri atas tiga pilar yakni: ASEAN Political and Security Community (APSC)/Masyarakat Politik dan Keamanan ASEAN, ASEAN Economic Community (AEC)/Masyarakat Ekonomi ASEAN, dan ASEAN Socio-Cultural Community (ASCC)/Masyarakat Sosial Budaya ASEAN.

Indonesia saat ini telah memasuki era Masyarakat Ekonomi ASEAN. Topik yang menarik untuk dikaji dari MEA yakni pasar tunggal ASEAN dan basis produksi yang terdiri atas lima elemen antara lain: (1) barang (free flow of goods), (2) jasa (free flow of services), (3) investasi (free flow of investment), (4) modal (free flow of capital) dan (5) tenaga kerja terampil (free flow of skilled labour). Elemen yang akan dibahas lebih lanjut dalam makalah ini terkait tenaga kerja terampil. Sumber daya manusia merupakan kekuatan Indonesia dikarenakan negara ini memiliki jumlah penduduk terbesar di antara negara anggota ASEAN dan juga negara dengan penduduk terbesar keempat di dunia. Sehingga Indonesia memiliki potensi yang luar biasa untuk mengekspansi pasar tenaga kerja di ASEAN dengan pekerja migran Indonesia/tenaga kerja Indonesia (PMI/TKI) yang dimiliki.

Statistik Badan Nasional Penempatan dan Perlindungan Tenaga Kerja Indonesia (BNP2TKI) menunjukkan penempatan PMI/TKI pada tahun 2011 sebanyak 586.802 orang, selanjutnya 494.609 orang (2012), 512.168 orang (2013), 429.872 orang (2014) dan 275.736 orang di tahun 2015. Statistik tersebut menunjukkan angka yang cukup signifikan. Fakta yang menarik dari migrasi pekerja Indonesia di kawasan Asia Tenggara yakni Malaysia menjadi negara penempatan dengan jumlah terbesar. Disusul Singapura, Brunei Darussalam dan Thailand. Keempat negara anggota ASEAN ini berada di antara 25 negara penempatan TKI/PMI dari sebaran 170 negara.

Beberapa kajian mengenai tenaga kerja di negara anggota ASEAN dan kaitannya dengan masyarakat ASEAN pernah dipublikasikan oleh Nguyen Huy Hoàng (2013), Aniceto C. Orbeta, Jr (2013) dan Natenapha Wailerdsak (2013) dan Achmad Zulfikar (2015). Hoang dalam publikasinya menyatakan bahwa masyarakat ekonomi ASEAN merupakan peluang bagi negara anggota CLMV (Kamboja, Laos, Myanmar dan Viet Nam) dengan meningkatkan kualitas tenaga kerja agar dapat berintegrasi dalam pasar tenaga kerja ASEAN. Selanjutnya, Orbeta Jr. dalam publikasinya menyatakan bahwa pergerakan pekerja tidak terampil dan semi termapil seyogyanya dapat diakomodasi dalam masyarakat ekonomi ASEAN agar penerapannya dapat lebih baik dengan didasarkan pada realita bahwa sektor agrikultur, 
manufaktur dan jasa didominasi oleh pekerja tidak terampil dan semi terampil yang mendominasi migrasi kerja di ASEAN.

Kemudian, Wailerdsak menyatakan bahwa masyarakat ekonomi ASEAN menjadi salah satu motivasi bagi pemerintah Thailand untuk meningkatkan investasi di luar negeri, khususnya negara-negara ASEAN dalam rangka meningkatkan daya kompetisi dan menyelesaikan permasalahan kekurangan tenaga kerja. Sedangkan, Zulfikar menyatakan bahwa pemetaan posisi pekerja migran Indonesia menuju masyarakat Ekonomi ASEAN 2015 masih mengkhawatirkan. Profesi yang ditekuni oleh tenaga kerja Indonesia (TKI) yang bekerja di luar negeri hampir didominasi sektor informal yakni bekerja sebagai Penata Laksana Rumah Tangga (PLRT). Apabila dikaitkan dengan MEA 2015, maka profesi ini tidak menjanjikan untuk mendongkrak daya tawar pekerja Indonesia dalam MEA 2015. Hal ini sekaligus menunjukkan ironi bahwa bangsa Indonesia belum mampu memenuhi kebutuhan pasar tenaga kerja terampil di ASEAN.

Nilai kebaruan (novelty) dari makalah ini yakni mengurai lebih lanjut mengenai peluang dan tantangan pekerja migran Indonesia dalam masyarakat ekonomi ASEAN setelah pemberlakuannya sejak 31 Desember 2015 atau tepat ketika memasuki awal tahun 2016. Jika dibandingkan dengan kajian yang telah dilakukan sebelumnya baik yang dilakukan oleh peneliti dari Viet Nam, Filipina dan Thailand bahkan kajian dari penulis pada publikasi sebelumnya masih melihat implikasi yang akan ditimbulkan jika MEA diberlakukan, sedangkan makalah ini memotret kondisi jelang satu tahun pemberlakuan MEA.

\section{KERANGKA TEORETIK}

\section{Regionalisme}

Di dalam studi Hubungan Internasional, Regionalisme memiliki irisan studi yang sangat erat dengan studi kawasan (area studies). Bahkan dalam aplikasi analisis, istilah region (kawasan) dengan regionalisme seringkali tumpang tindih. Oleh karena itu, definisi tentang regionalism akan banyak mengambil dari definisi-definisi yang berkembang dalam studi kawasan. Menurut Mansbaach dalam Nuraeini S dkk. (2010:1), region atau kawasan adalah "pengelompokan regional diidentifikasi dari basis kedekatan geografis, budaya, perdagangan dan saling ketergantungan ekonomi yang saling menguntungkan, komunikasi serta keikutsertaan dalam organisasi internasional". Lebih lanjut, Coulumbis dan Wolfe dalam Nuraeini S dkk. (2010:1-2) menyatakan ada empat kriteria untuk menunjuk sebuah kawasan yang ditentukan oleh tujuan analisis, salah satu yang terkait dengan ASEAN yakni kriteria geografis yakni mengelompokkan negara berdasarkan lokasinya dalam benua, subbenua, kepulauan dan lain sebagainya seperti: Eropa dan Asia, termasuk Asia Tenggara.

Teori konvergensi (convergence theory) dikemukakan oleh Hurrel yang merupakan salah satu dari tiga cara bagaimana faktor-faktor domestik terkait dengan regionalisme kontemporer, selain regionalisme dan state coherence dan tipe rezim dan demokratisasi. Teori ini memahami dinamika kerjasama regional dan integrasi ekonomi dalam kerangka bertemunya atau bersatunya berbagai pilihan kebijakan domestik dari negara-negara. Menurut Hurrel dalam Nuraeini S dkk. (2010:62-63) teori konvergensi memang terlihat sangat menekankan pada permasalahan ekonomi dan kebijakan perekonomian suatu negara, namun kita dapat menggunakan teori ini pada tataran permasalahan yang lebih umum dalam regionalisme kontemporer. 
Masyarakat ekonomi ASEAN bersama dua pilar lainnya merupakan kebijakan yang telah disepakati 10 negara anggota ASEAN. Kebijakan yang menjadi fokus dalam kajian ini yakni bidang ketenagakerjaan. Negara-negara anggota ASEAN menyadari bahwa potensi penyerapan tenaga kerja di antara negara-negara anggota ASEAN sangat tinggi. Utamanya, Indonesia sebagai anggota dengan luas wilayah terbesar diantara negara anggota ASEAN yang lain. Dalam konteks ketenagakerjaan, negara anggota ASEAN dapat dibagi ke dalam dua pihak yakni negara pengirim (sending countries) dan negarap penerima (receiving countries). Indonesia, Filipina, Kamboja, Laos, Myanmar dan Viet Nam merupakan negara pengirim, sedangkan Malaysia, Singapura, Brunei Darussalam dan Thailand merupakan negara penerima. Tetapi hal yang mempertemukan kepentingan negara-negara ini yakni mereka dapat memasuki pasar tenaga kerja satu sama lain sebagia satu kawasan. Teori ini akan digunakan untuk menjelaskan bagaimana peluang dan tantangan pekerja migran Indonesia dalam masyarakat ekonomi ASEAN dengan kondisi dan potensi yang dimiliki.

\section{HASIL DAN PEMBAHASAN}

\section{Kondisi Pekerja Migran Indonesia di Negara Anggota ASEAN}

Pekerja Migran Indonesia/Tenaga Kerja Indonesia (TKI) adalah setiap warga negara Indonesia yang memenuhi syarat untuk bekerja di luar negeri dalam hubungan kerja untuk jangka waktu tertentu dengan menerima upah. (Pasal 1 UU No. 39 Tahun 2004) Pasal 35 UU No. 39/2004 menjelaskan syarat-syarat TKI untuk bekerja di luar negeri, antara lain: (1) berusia sekurang-kurangnya 18 tahun, kecuali bagi calon TKI yang dipekerjakan pada pengguna perseorangan/rumah tangga sekurang-kurangnya berusia 21 tahun; (2) sehat jasmani dan rohani; (3) tidak dalam keadaan hamil bagi calon tenaga kerja perempuan; (4) berpendidikan sekurang-kurangnya lulus SLTP atau yang sederajat; (5) terdaftar di Dinas Ketenagakerjaan di daerah tempat tinggalnya; (6) memiliki dokumen lengkap.

Penjelasan di atas secara jelas mendefinisikan bahwa pekerja migran Indonesia atau tenaga kerja Indonesia adalah warga negara Indonesia dengan kriteria: 1) memenuhi syarat untuk bekerja di luar negeri, 2) hubungan kerja untuk jangka waktu tertentu dan 3) menerima upah. Hal ini berlaku untuk PMI/TKI yang berasal dari berbagai wilayah di Indonesia. Seperangkat standar bagi pekerja migran Indonesia juga telah ditetapkan oleh pemerintah, sehingga penyimpangan/pelanggaran atas standar tersebut dapat mengakibatkan pekerja migran Indonesia tidak dapat dipenuhi hak-haknya.

Pekerja migran Indonesia seperti yang telah didefinisikan merupakan PMI/TKI yang legal dan telah melalui serangkaian prosedur yang ditetapkan oleh pemerintah. Perekrutan TKI ini bisa difasilitasi oleh pemerintah melalui Badan Nasional Penempatan dan Perlindungan TKI (BNP2TKI)/Balai Pelayanan Penempatan dan Perlindungan TKI (BP3TKI). maupun Pelaksana Penempatan TKI Swasta (PPTKIS). Selain berperan sebagai fasilitator penempatan, BNP2TKI/BP3TKI juga mengawasi proses penempatan yang difasilitasi oleh PPTKIS. Berikut data penempatan TKI dalam 6 tahun terakhir (2011-Oktober 2016). 
Grafik 1. Penempatan Tenaga Kerja Indonesia Tahun 2011-Okt. 2016

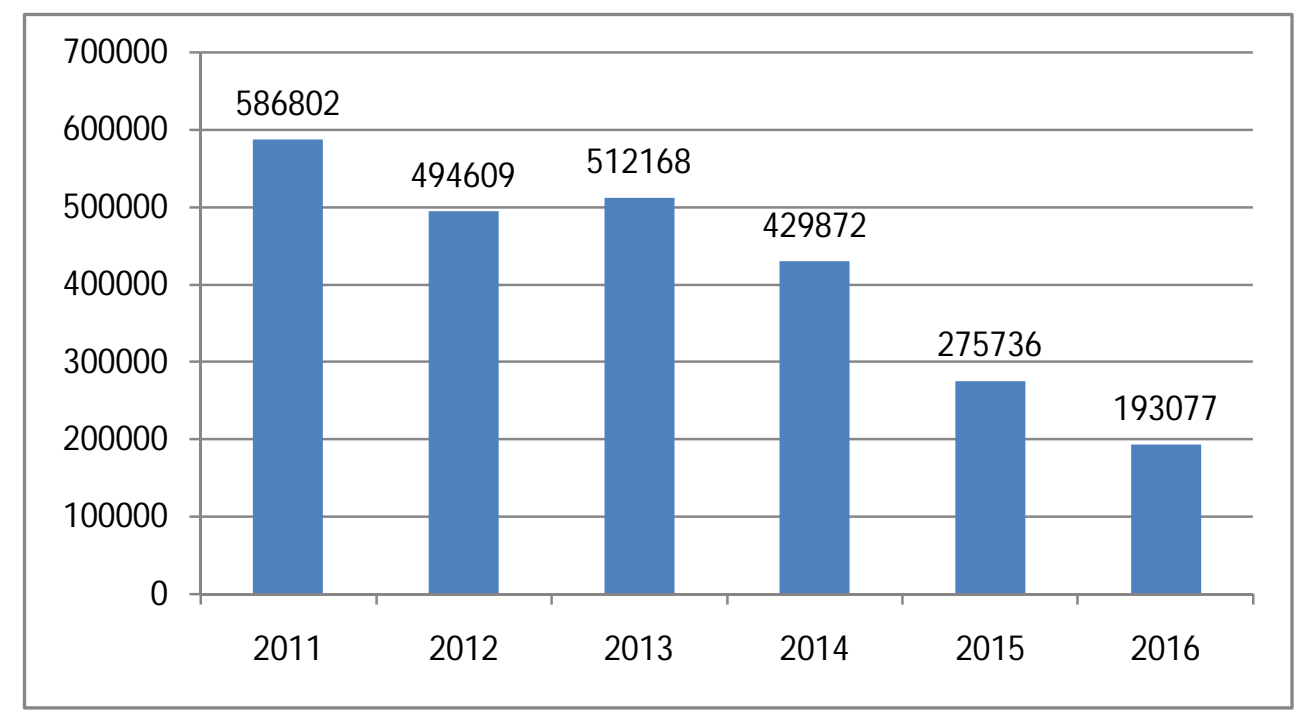

Sumber: Data Penempatan dan Perlindungan TKI Periode Bulan Oktober Thn. 2016 (BNP2TKI)

Data di atas menunjukkan penempatan TKI dari tahun 2011 hingga 2016 mengalami penurunan yang signifikan. Walaupun pada tahun 2013 sempat mengalami kenaikan, tetapi penempatan TKI pada tahun 2015 jika dibandingkan tahun sebelumnya (2014) mengalami penurunan yang drastis. Kondisi ini terus berlanjut hingga Oktober 2016. Selanjutnya, Pekerja migran Indonesia tersebar di 150 negara berdasarkan 25 negara penempatan dengan jumlah TKI terbesar dipaparkan sebagai berikut:

Tabel 1. Negara Penempatan Tenaga Kerja Luar Negeri Indonesia Periode 2011-Okt. 2016

\begin{tabular}{|c|c|c|c|c|c|c|c|}
\hline \multirow{2}{*}{ No. } & \multirow{2}{*}{ Negara } & \multicolumn{6}{|c|}{ Tahun } \\
\hline & & $2011 *$ & $2012 * *$ & $2013 * *$ & $2014 * *$ & $2015 * *$ & $2016 * * *$ \\
\hline 1. & Malaysia & 134.120 & 134,069 & 150,250 & 127,827 & 97,635 & 73,866 \\
\hline 2. & Taiwan & 78.865 & 81,071 & 83,544 & 82,665 & 75,303 & 63,018 \\
\hline 3. & Saudi Arabia & 137.835 & 40,655 & 45,394 & 44,325 & 23,000 & 12,096 \\
\hline 4. & Hongkong & 50.301 & 45,478 & 41,769 & 35,050 & 15,322 & 11,755 \\
\hline 5. & Singapura & 47.786 & 41,556 & 34,655 & 31,680 & 20,895 & 13,454 \\
\hline 6. & $\begin{array}{l}\text { Uni Emirat } \\
\text { Arab }\end{array}$ & 39.917 & 35,888 & 44,505 & 17,962 & 7,619 & 2,273 \\
\hline 7. & Qatar & 16.616 & 20,380 & 16,237 & 7,862 & 2,460 & 1,119 \\
\hline 8. & Korea Selatan & 11.392 & 13,593 & 15,374 & 11,848 & 5,501 & 3,545 \\
\hline 9. & $\begin{array}{l}\text { Amerika } \\
\text { Serikat }\end{array}$ & 13.749 & 15,353 & 15,021 & 9,233 & 1,029 & 226 \\
\hline 10. & Oman & 7.306 & 10,719 & 10,719 & 10,719 & 6,766 & 864 \\
\hline 11. & $\begin{array}{l}\text { Brunei } \\
\text { Darussalam }\end{array}$ & 10.804 & 13,146 & 11,269 & 11,616 & 9,993 & 6,859 \\
\hline 12. & Bahrain & 4.379 & 6,328 & 5,384 & 5,472 & 2,570 & 110 \\
\hline 13. & Jepang & 2.508 & 3,293 & 3,042 & 2,428 & 468 & \\
\hline 14. & Italia & 3.408 & 3,691 & 3,746 & 1,295 & 1,516 & 737 \\
\hline 15. & Kuwait & 2.723 & 2,518 & 2,534 & 1,714 & 210 & 788 \\
\hline 16. & China & 1.072 & 1,967 & 2,055 & 915 & 108 & 57 \\
\hline
\end{tabular}




\begin{tabular}{|l|l|r|r|r|r|r|r|}
\hline 17. & Spanyol & 1.484 & 1,746 & 1,417 & 889 & 268 & 91 \\
\hline 18. & Turki & 1.016 & 1,209 & 1,518 & 1,246 & 1,108 & 489 \\
\hline 19. & Afrika Selatan & 1.272 & 1,388 & 905 & 587 & 113 & - \\
\hline 20. & Mauritius & 478 & 982 & 1,017 & 838 & 144 & - \\
\hline 21. & Thailand & 1.113 & 1,035 & 1,041 & 717 & 90 & - \\
\hline 22. & Belanda & 592 & 798 & 1,176 & 796 & 52 & - \\
\hline 23. & Kepulauan Fiji & 556 & 970 & 848 & 902 & 246 & - \\
\hline 24. & Australia & 526 & 945 & 1,012 & 644 & 77 & - \\
\hline 25. & Jerman & 299 & 697 & 1,168 & 556 & 194 & 107 \\
\hline 26. & Lainnya & 59.059 & 17,017 & 16,568 & 11,664 & 3,049 & 1.623 \\
\hline \multicolumn{2}{|c|}{ Total } & 586.802 & 494,609 & 512,168 & 429,872 & 275,736 & 193,077 \\
\hline
\end{tabular}

Sumber: Data Penempatan dan Perlindungan TKI Tahun *2011-2013, **2015, ***Okt. 2016 (BNP2TKI)

Data di atas menunjukkan Malaysia merupakan negara tujuan dengan penempatan tertinggi setiap tahun selama 6 tahun terakhir (2011-2015). Di posisi berikutnya adalah Taiwan, Saudi Arabia, Hongkong dan Singapura di urutan kelima. Lebih lanjut, kondisi TKI di Negara Anggota ASEAN dipaparkan sebagai berikut:

Grafik 2. Kondisi TKI di Negara Anggota ASEAN

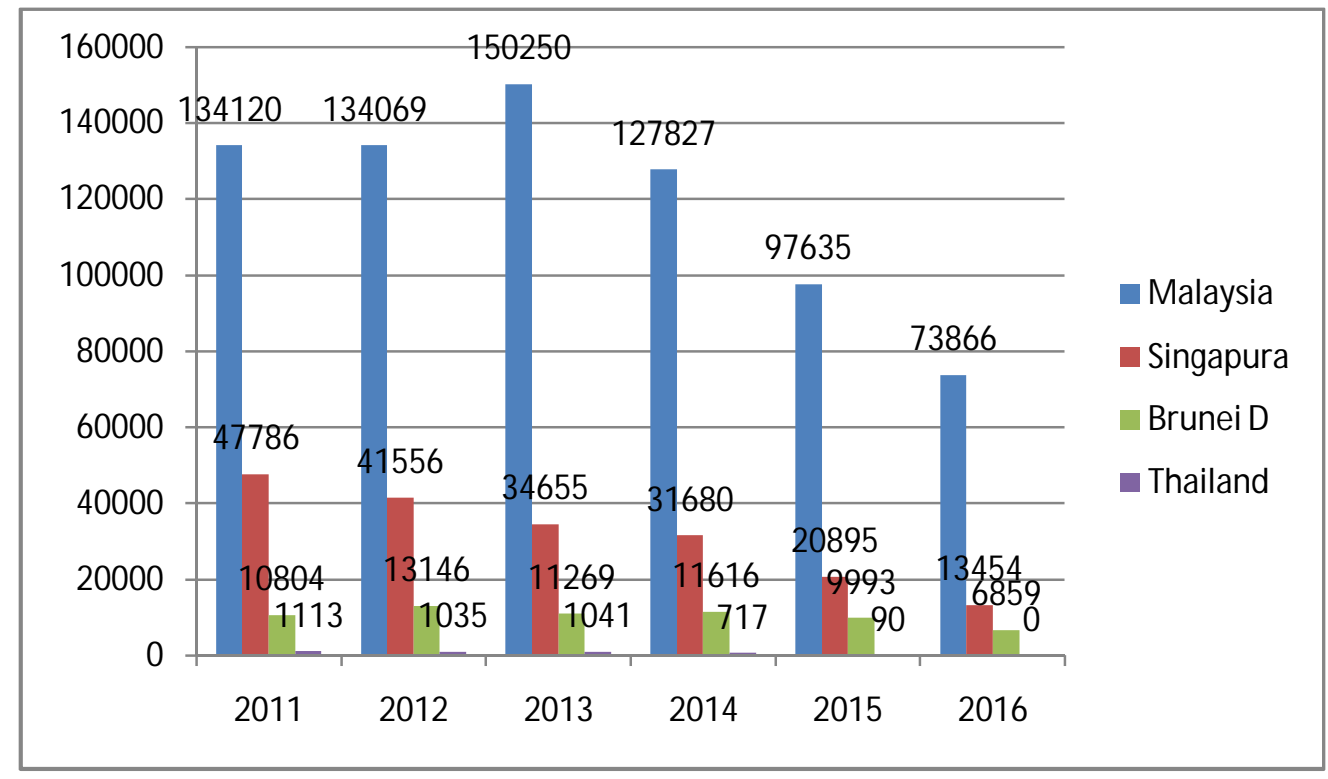

Sumber: Diolah oleh Penulis dari data BNP2TKI

Penempatan pekerja migran Indonesia/Tenaga kerja Indonesia (PMI/TKI) di negaranegara anggota ASEAN pada data Negara Penempatan Tenaga Kerja Luar Negeri Indonesia menunjukkan hanya empat negara yang masuk dalam 25 besar negara penempatan yakni Malaysia (urutan 1), Singapura (urutan 5), Brunei Darussalam (urutan 11) dan Thailand (urutan 21). Data di atas lebih spesifik menunjukkan kondisi TKI di negara-negara tersebut. Jika diperhatikan secara seksama, penempatan TKI di Malaysia relatif stabil pada 2011 dan 2012, kemudian terjadi peningkatan pada 2013 dan penurunan kembali pada 2014. TKI pada tahun 2015 mengalami penurunan yang cukup besar jika dibandingkan tahun-tahun sebelumnya. Demikian juga yang terjadi di Singapura dan Brunei Darussalam. Bahkan, penempatan TKI di Thailand sampai Oktober 2016 belum ada. Selanjutnya dipaparkan posisi/jabatan yang ditempati oleh TKI di negara penempatan, sebagai berikut: 
Tabel 2. Jabatan TKI di Negara Penempatan Periode 2011-2015

\begin{tabular}{|c|c|c|c|c|c|c|}
\hline \multirow{2}{*}{ No. } & \multirow{2}{*}{ Jabatan } & \multicolumn{5}{|c|}{ Tahun } \\
\hline & & $2011 *$ & $2012 * *$ & $2013 * *$ & $2014 * *$ & $2015^{* *}$ \\
\hline 1. & Dosmetic Worker & 267.231 & 164.981 & 168.318 & 133.390 & 52.328 \\
\hline 2. & Caregiver/Caretaker & 48.492 & 52.565 & 48.188 & 49.069 & 44.941 \\
\hline 3. & Plantation Worker & 39.622 & 36.478 & 47.598 & 47.790 & 38.526 \\
\hline 4. & Operator & 40.847 & 40.347 & 46.799 & 38.836 & 35.187 \\
\hline 5. & Deck Hand & - & 12.283 & 11.249 & 10.410 & 1.166 \\
\hline 6. & Lainnya & 191.610 & 187.955 & 190.016 & 150.377 & 103.588 \\
\hline \multicolumn{2}{|r|}{ Total Keseluruhan } & 586.802 & 494,609 & 512,168 & 429,872 & 275,736 \\
\hline
\end{tabular}

Sumber: Data Penempatan dan Perlindungan TKI Tahun *2011-2013 \& **2015 (BNP2TKI)

Data di atas menunjukkan 5 jabatan teratas yang ditempati oleh TKI di negara penempatan. Posisi pertama ditempati oleh TKI yang bekerja sebagai domestic worker / penata laksana rumah tangga, selanjutnya caregiver/caretaker di posisi kedua, posisi ketiga ditempati plantation worker, posisi keempat oleh operator dan posisi kelima ditempati deck hand. Hal ini menunjukkan bahwa pekerja migran Indonesia di luar negeri masih berada pada kategori tenaga kerja tidak terampil/berketerampilan rendah seperti domestic worker/penata laksana rumah tangga, caregiver/caretaker dan plantation worker. Maupun tenaga kerja semi-terampil pada posisi operator maupun deck hand.

Berdasarkan data di atas maka dapat dipahami bahwa kondisi pekerja migran Indonesia di negara anggota ASEAN menempatkan Malaysia sebagai negara penempatan dengan jumlah terbesar mencapai hampir seperempat dari jumlah penempatan TKI setiap tahunnya, diikuti Singapura, Brunei Darussalam dan Thailand. Sedangkan tenaga kerja yang ditempatkan juga masih berada pada kategori tidak terampil dan semi terampil.

\section{Kondisi Ketenagakerjaan Indonesia terhadap Mutual Recognitions Agreements (MRAs)}

Arus bebas tenaga kerja terampil ASEAN (free flow of skilled labour) merupakan poin kelima dari karakteristik pasar tunggal dan basis produksi sebagaimana telah disebutkan dalam cetak biru Masyarakat Ekonomi ASEAN (MEA) Tahun 2015. Dalam cetak biru tersebut disebutkan bahwa penguatan melalui riset kapabilitas dari setiap negara anggota ASEAN untuk mempromosikan kemampuan tenaga kerja, penempatan tenaga kerja, dan pengembangan pasar tenaga kerja berbasis jaringan informasi diantara negara anggota ASEAN merupakan salah satu bagian penting dalam kesekapakatan MEA 2015. (ASEAN, 2011:29-30)

Berdasarkan cetak biru tersebut, jadwal strategi untuk MEA 2015 khususnya arus bebas tenaga kerja terampil ASEAN di bagi ke dalam dua aksi prioritas yakni tahun 20082009 dan 2014-2015. Fase yang seharusnya sudah dilalui oleh negara anggota ASEAN dalam fase 2008-2009 dengan dua poin aksi yakni: (1) menyelesaikan Mutual Recognition Aggrements (MRAs) untuk bidang jasa profesional utama, termasuk sektor jasa investasi tahun 2008, dan (2) mengembangkan kompetensi inti (mengacu kepada kemampuan dan kualifikasi) untuk pekerjaan yang membutuhkan keterampilan terhadap prioritas sektor jasa 
tahun 2009. Sedangkan fase 2014-2015 dengan poin aksi untuk mengembangkan kompetensi inti (mengacu ke kemampuan dan kualifikasi) untuk pekerjaan yang membutuhkan keterampilan terhadap seluruh sektor jasa tahun 2015. (ASEAN, 2011:54)

Paparan di atas memang tidak spesifik menyebutkan bidang prioritas yang disepakati oleh negara anggota ASEAN, dikarenakan cetak biru tersebut akan diturunkan lagi ke dalam kesepakatan yang bersifat teknis. Dikutip dari website Kementerian Ketenagakerjaan (Kemenaker) pemerintah Indonesia memberikan perhatian khusus terhadap 8 profesi yang menjadi prioritas karena Mutual Recognition Aggrements (MRA)-nya telah ditandatangai oleh negara anggota ASEAN. Delapan profesi prioritas yakni akuntansi, teknik, survei, arsitektur, keperawatan, kesehatan, perawatan gigi dan pariwisata. (Kemenaker, 2014)

Sebagai tindaklanjut kesepakatan MRA ini, pemerintah pun terus berupaya untuk memperkuat kerjasama antara negara anggota ASEAN dalam menetapkan dan memperluas kerjasama implementasi MRA melalui peningkatan produktivitas dan kompetensi Sumber Daya Manusia (SDM) dengan membangun pusat pelatihan kejuruan. Selain itu, disiapkan juga pelatihan dasar untuk kompetensi dan sistem sertifikasi, akselerasi standar kompetensi nasional, serta menerapkan Kerangka Kualifikasi Nasional Indonesia (KKNI) dan memperkuat sistem kerja sama dengan lembaga yang terkait. (Kemenaker, 2014)

Menteri Ketenagakerjaan, Hanif Dhakiri mengatakan sejumlah negara di kawasan ASEAN telah memiliki kerangka untuk mempromosikan pergerakan bebas tenaga kerja terampil. Tetapi, terdapat pula sebagian negara lain belum memiliki kerangka tersebut meliputi kualifikasi nasional penuh sekaligus penerapan sertifikasi tenaga kerja. Pelaksanaan MEA diakui Menaker dapat menimbulkan dampak negatif terhadap dunia ketenagakerjaan di Indonesia jika tenaga kerja kita tidak menyiapkan kompetensinya dengan baik. (Kemenaker, 2014) Dalam kesempatan lain, Menteri Ketenagakerjaan Hanif Dhakiri menegaskan dibutuhkan soliditas kuat antara pemerintah pusat maupun pemerintah daerah dalam menghadapi pemberlakukan Masyarakat Ekonomi ASEAN (MEA). Hal itu dengan lebih meningkatkan sinergisitas program kegiatan ketenagakerjaan. (Pikiran Rakyat, 2016)

Penjelasan dari pemerintah seperti yang telah dipaparkan di atas memberikan penegasan bahwa baru delapan profesi prioritas yang disepakati oleh negara anggota ASEAN untuk diintegrasikan antara lain: akuntansi, teknik, survei, arsitektur, keperawatan, kesehatan, perawatan gigi dan pariwisata. Namun tidak menutup kemungkinan ada lagi sektor yang bertambah seiring kesepakatan MRAs yang terus diupayakan oleh negara anggota ASEAN untuk disepakati. Selengkapnya kondisi setiap profesi yang telah disepakati dalam MRAs dipaparkan sebagai berikut:

\section{Akuntansi}

Jasa akuntansi merupakan salah satu sektor jasa yang penting untuk menegakkan regulasi terkait dengan keuangan. Kondisi akuntan di Indonesia pada 2013 menurut Ikatan Akuntan Indonesia (IAI) tercatat 13.933 akuntan. Sementara di Singapura, asosiasi akuntan setempat mencatat 25.842 akuntan. Malaysia sebanyak 29.413 akuntan dan Thailand sebanyak 51.298 akuntan. Indonesia dalam masyarakat ekonomi ASEAN (MEA) membutuhkan akuntan yang berkualifikasi dan profesional yang mampu mendukung aktivitas ekonomi. Indonesia perlu menghasilkan akuntan yang memiliki sertifikasi profesi berstandar 
internasional. Hal ini untuk mempertemukan antara penawaran dan pasar tenaga kerja. Lembaga jasa keuangan membutuhkan kolaborasi antara lembaga pendidikan profesional, pemerintah, asosiasi profesi dan swasta untuk meningkatkan minat angkatan kerja muda untuk menjadikan akuntan sebagai profesi yang menjanjikan.

Dalam hal sumber daya manusia, kuantitas dan kualitas akuntan Indonesia memerlukan percepatan. Daya saing akuntan Indonesia tidak hanya pada tingkat kawasan ASEAN tetapi juga pada tingkat global. Hal yang penting untuk diperhatikan bahwa keunikan standar akuntan di Indonesia juga menjadi keunggulan bagi akuntan Indonesia. Hal yang juga perlu diperhatikan yakni kekurangan infrastruktur pendidikan, utamanya pendidikan profesional perlu mendapat perhatian melalui kebijakan pemerintah.

\section{Teknik}

Tujuan dari MRAs di sektor (jasa) teknik yakni memfasilitasi perdagangan dan aktivitas ekonomi yang simultan diantara para pihak melalui kompetensi sumber daya manusia yang memenuhi standar, kualifikasi, sertifikasi dan lisensi. Dalam sektor teknik, MRAs ditujukan untuk memfasilitasi perpindahan jasa teknik profesional dan pertukaran informasi untuk mengadopsi praktik terbaik dalam standar. Di Indonesia teknik berdasarkan kuriklum yang diterapkan terbagi ke dalam 12 tipe antara lain: (1) Teknik Sipil, (2) Teknik Mesin, (3) Teknik Elektro, (4) Teknik Fisika, (6) Teknik Perminyakan, (6) Teknik Industri, (7) Geodesi, (8) Teknik Kelautan, (9) Teknik Kimia, (10) Teknik Lingkungan, (11) Teknik Pertambangan dan (12) Teknik Penerbangan.

Sementara jika dibandingkan dengan negara anggota ASEAN yang lain pembagian keteknikan di Indonesia sangat berbeda. Salah satu indikator dalam menentukan kondisi yang dihadapi insinyur di Indonesia adalah pemenuhan insinyur di dalam negeri untuk melihat pertumbuhan lulusan teknik yang dihasilkan setiap tahun di Indonesia. Data yang diperoleh dari Persatuan Insinyur Indonesia menyebutkan bahwa sarjana teknik di Indonesia masih jauh jika dibandingkan dengan Malaysia. Selengkapnya pada grafik berikut:

Grafik 3. Populasi Sarjana Teknik

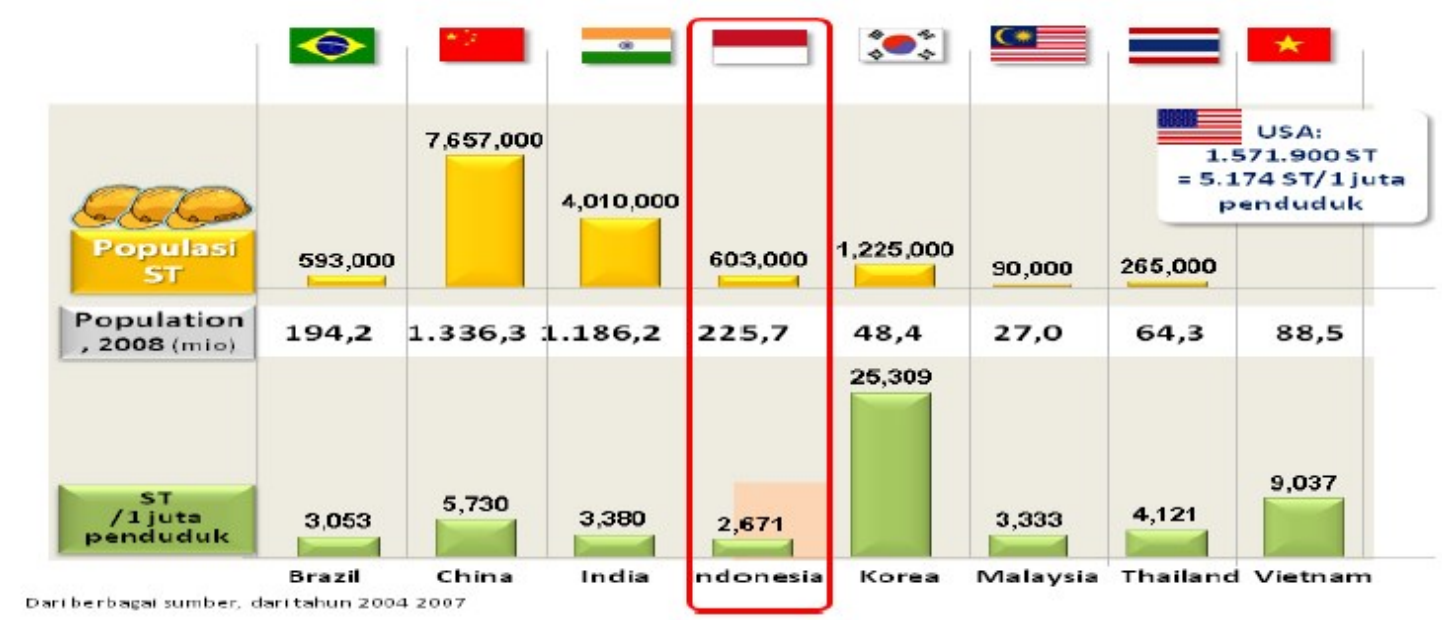

Sumber: Persatuan Insinyur Indonesia (PII), 2013 
Grafik di atas menunjukkan bahwa populasi sarjana teknik di Indonesia per 1 juta penduduk masih sangat kecil dibandingkan dengan Viet Nam, Malaysia dan Thailand. Indonesia masih kekurangan 1,2 juta insinyur. Padahal Indonesia idealnya memiliki 2 juta insinyur, sementara saat ini hanya memenuhi 600-700 ribu. Menurut PII, jika permintaan semakin meningkat dan pada tahun 2030 tidak ada perubahan kebijakan yang dapat mendorong pertumbuhan yang cepat dari tingkat rekayasa untuk setiap tahun sekitar 15.000 kekurangan insinyur Indonesia akan diisi tenaga kerja asing.

\section{Survei}

Surveyor adalah warga negara dari negara-negara anggota ASEAN yang telah menyelesaikan pendidikan sarjana di sebuah universitas atau perguruan tinggi dalam program survei yang telah diakui oleh otoritas kompetensi. Kedua, survei profesional mengacu pada surveyor yang memiliki pengalaman atau keahlian teknis sesuai dengan ketentuan yang ditetapkan oleh otoritas kompetensi.

Sektor survei ini di semua negara ASEAN diselenggarakan oleh instansi pemerintah, sementara pada sektor lain MRAs didelegasikan kepada asosiasi profesional dalam koordinasi dengan instansi pemerintah terkait. Salah satu alasan mengapa demikian adalah karena bidang survei pemetaan berhubungan langsung dengan otoritas geografis suatu negara dengan kata lain juga terkait dengan menyatakan kedaulatan dari segi geografi.

Di Indonesia, yang merupakan representasi dari pemerintah Indonesia di bidang survei dalam kerangka MRAs didelegasikan kepada Badan Informasi Geospasial (BIG atau sebelumnya dikenal sebagai Badan Koordinasi Survei dan Pemetaan). Selain itu, tidak semua informasi yang dimiliki oleh lembaga bidang geospasial dapat dipublikasikan. Di Indonesia, bidang survei dan pemetaan sangat penting karena situasi geografis Indonesia merupakan negara kepulauan dengan lebih dari tujuh belas ribu pulau yang membentang di wilayah Indonesia. Surveyor berkualitas tinggi dibutuhkan untuk dapat menyediakan produk-produk pemetaan yang komprehensif di Indonesia.

Tabel 3. Kompetensi Surveyor Pemetaan

\begin{tabular}{|c|c|c|c|}
\hline \multicolumn{2}{|c|}{ Education } & \multirow{2}{*}{ Qualification } & \multirow{2}{*}{$\begin{array}{l}\text { Training / } \\
\text { Experience }\end{array}$} \\
\hline Academic & Vocational & & \\
\hline $\mathrm{S}_{3}$ & & IX & Expert 3 \\
\hline S2 & & $\begin{array}{l}\text { VIII } \\
\text { VII }\end{array}$ & $\begin{array}{l}\text { Expert } 2 \\
\text { Expert } 1\end{array}$ \\
\hline \multirow[t]{2}{*}{ S1 } & $\mathrm{D} 4$ & VI & Technician / Analyst 3 \\
\hline & $\mathrm{D}_{3}$ & $\mathrm{~V}$ & Technician / Analyst 2 \\
\hline \multirow{2}{*}{$\begin{array}{l}\text { SM / high } \\
\text { school }\end{array}$} & D2 & IV & Technician / Analyst 1 \\
\hline & D1 & $\begin{array}{c}\text { III } \\
\text { II }\end{array}$ & $\begin{array}{l}\text { Operators } 3 \\
\text { Operators } 2\end{array}$ \\
\hline $\begin{array}{c}\text { SD / } \\
\text { elementary } \\
\text { school }\end{array}$ & & I & Operators 1 \\
\hline
\end{tabular}

Sumber: Badan Informasi Geospasial (BIG), 2013

Ada beberapa hal yang menarik untuk dicatat sebagai gambaran umum dari kompetensi pekerja survei di Indonesia. Pertama, secara umum kualitas tenaga kerja survei 
Indonesia sangat baik. Jika dilihat berdasarkan kategorisasi kompetensi pekerja survei Indonesia umumnya di atas kualifikasi VII, yang berarti bahwa rata-rata, sudah pada tingkat Ahli/Expert $1 \mathrm{ke}$ atas. Bahkan, jika dibandingkan dengan kualitas pekerja survei dengan negara-negara ASEAN lainnya, kualitas survei di Indonesia jauh lebih baik. Namun, sayangnya tidak ada data kuantitatif untuk mendukung penjelasan ini.

Hal yang perlu mendapat perhatian juga yakni pertama tidak adanya data primer termasuk jumlah pekerja atau ahli survei di Indonesia termasuk kebutuhan per-tahun terhadap survei, jumlah lulusan perguruan tinggi yang berkaitan dengan survei seperti bidang geografi, geologi, ilmu bumi dan ilmu terkait lainnya. Kedua, ketiadaan asosiasi surveyor profesional Indonesia. Jika melihat kebijakan pemerintah, khususnya dalam hal organisasi profesi di bidang pemetaan sangat disayangkan bahwa penyerapan lulusan dari sarjana yang berkaitan dengan survei di Indonesia masih rendah. Hal ini dikarenakan peluang untuk mengembangkan ilmunya terkait pendidikan dan kemampuan yang didapatkan dari perguruan tinggi belum memadai.

\section{Arsitektur}

Arsitek adalah seseorang yang merancang bangunan dan memberikan saran implementasi serta bertindak sebagai pengawas dan pelaksana bangunan. Inti dari arsitek yang merancang atau mendesain, jasa arsitektur atau jasa konstruksi memberikan kontribusi pada distribusi pekerjaan sektor jasa. Arsitektur memiliki daya saing yang baik, pekerja terampil di bidang arsitek berdasarkan kualifikasi nasional terdiri dari teknisi/mandor/tukang las. Sementara kualifikasi untuk ahli dibagi menjadi tiga kategori utama, yaitu ahli utama, ahli menengah dan ahli muda. Klasifikasi terkait ASEAN dibagi menjadi dua kategori untuk jasa arsitek disebut ASEANachitect (AA), sedangkan untuk insinyur disebut the ASEAN Chartered Professional Engineer (ACPE). Kuantitas jasa arsitek di Indonesia masih kurang memadai, mengacu pada jumlah anggota Ikatan Arsitek Indonesia (IAI) hanya 14.842 orang.

Hal yang perlu diperhatikan dari sektor arsitektur ini antara lain: pertama kualitas pendidikan arsitektur yang tidak merata. Hanya ada sekitar 140 perguruan tinggi yang tersebar dari Jakarta ke Maluku Utara dan penyebarannya berpusat di pulau Jawa. Kedua, durasi waktu penyelesaian pendidikan arsitektur yakni 4 tahun yang dipersyaratkan secara nasional yakni 5 tahun. Kedua hal ini perlu mendapat perhatian pemerintah yakni meninjau lembaga pendidikan dimana semua daerah memiliki kesempatan yang sama untuk mendapatkan layanan pendidikan arsitek. Namun hal yang juga penting yakni memperhatikan kualitas daripada kuantitas sebagai faktor penentu keberhasilan sumber daya manusia Indonesia di ASEAN dan pasar global yang kompetitif.

\section{Keperawatan}

Perawat adalah seseorang yang memiliki keahlian di bidang layanan yang mereka secara resmi dan secara administratif telah mendapat pengakuan dan lisensi dari pihak berwenang yang ditunjuk oleh masing-masing negara. Hanya perawat yang memiliki daya saing tinggi yang memiliki kesempatan untuk bisa bersaing di "pasar" jasa perawat. Selain itu, peran Negara menjadi titik sangat penting dalam menentukan dan meningkatkan 
kualifikasi tenaga keperawatan untuk dapat memanfaatkan secara optimal pelayanan keperawatan dalam era masyarakat ekonomi ASEAN.

Profesi keperawatan memiliki pangsa terbesar dalam persentase tenaga kesehatan, tidak hanya di Indonesia tetapi juga secara global. Di Indonesia, proporsi perawat dalam jumlah sebanyak 173.948 orang, diikuti oleh bidan. Selanjutnya, seiring dengan perkembangan dan dinamika global, mencatat bahwa perawat merupakan salah satu profesi yang mengalami kecenderungan meningkat dalam dekade terakhir kebutuhan tidak hanya di tingkat ASEAN tetapi juga secara global. Pesatnya pertumbuhan lansia yang melonjak drastis menjadi salah satu faktor tingginya permintaan untuk perawat. Berdasarkan data dari Kemenerian Kesehatan, perkiraan tenaga kesehatan dari luar negeri meningkat pesat dan perawat menempati porsi terbesar dari kebutuhan estimasi kenaikan tingkat permintaan terus melambung pada tahun 2014 sebanyak 9.280, sebanyak 13.100 di 2019 dan 2025 sebanyak 16.920. Sehingga dapat dikatakan ada peluang besar bagi perawat Indonesia di pasar tenaga kerja ASEAN.

Tabel 4. Perkiraan Kebutuhan Tenaga Kesehatan dari Luar Negeri

\begin{tabular}{|c|l|c|c|c|}
\hline No. & Health Workers & $\mathbf{2 0 1 4}$ & $\mathbf{2 0 1 9}$ & $\mathbf{2 0 2 5}$ \\
\hline 1. & Nurse & 9280 & 13100 & 16920 \\
\hline 2 & Physician Specialist & 1440 & 1800 & 2160 \\
\hline 3 & General Practitioners & 400 & 500 & 600 \\
\hline 4 & Dentist & 40 & 50 & 60 \\
\hline 5 & Midwife & 400 & 500 & 600 \\
\hline 6 & Medical technician & 400 & 500 & 600 \\
\hline 7 & SKM & 200 & 250 & 300 \\
\hline
\end{tabular}

Sumber: Pusat Perencanaan dan Pemanfaatan SDM Kesehatan, BPPSDMK, Kementerian Kesehatan, 2011

Hal yang dikhawatirkan yakni terjadinya ketidakseimbangan antara permintaan dan ketersediaan sumber daya manusia, masalah yang tidak hanya berkaitan dengan kebutuhan peningkatan daya saing tetapi juga untuk memenuhi kebutuhan dalam negeri. Selain itu, dari segi kualitas, standar kualitas profesi keperawatan belum memenuhi standar, seperti profesi keperawatan terlalu umum dan kebijakan yang tumpang tindih yang dibuat oleh pemerintah seperti proses sertifikasi dan pendidikan keperawatan yang minimal dan hanya terkonsentrasi di pulau Jawa. Kurangnya fasilitas pendukung terkait ketersediaan lembaga pendidikan keperawatan berkontribusi terhadap tantangan perawat untuk bersaing di pasar tenaga kerja ASEAN.

\section{(Tenaga) Kesehatan}

Sektor jasa praktisi medis merupakan salah satu sektor pelayanan kesehatan yang trennya sedang meningkat. Di Indonesia, jumlah permintaan dokter dari luar negeri diperkirakan akan terus meningkat hingga 2.160 spesialis dan 600 dokter umum di tahun 2025 . 
Tabel 5. Estimasi Penawaran Dokter dari Luar Negeri ke Indonesia

\begin{tabular}{|c|c|c|c|c|}
\hline No. & Health Workers & $\mathbf{2 0 1 4}$ & $\mathbf{2 0 1 9}$ & $\mathbf{2 0 2 5}$ \\
\hline 1 & Physician Specialist & 1440 & 1800 & 2160 \\
\hline 2 & General Practitioners & 400 & 500 & 600 \\
\hline \multicolumn{2}{|c|}{ Total } & 1840 & 2300 & 2760 \\
\hline
\end{tabular}

Sumber: CIT Thailand, 2012

Berdasarkan data dari International Centre for International Trade of Thailand (2012) kualitas praktisi medis profesional (dokter) Indonesia ditempatkan pada kualitas menengah, dan harus bersaing dengan Filipina dan Vietnam. Situasi ini persis situasi yang dihadapi oleh profesi keperawatan. Kondisi ini memaksa masuknya aliran dokter dari luar negeri, namun demikian pemerintah telah membuat regulasi bagi dokter asing di Indonesia. Kondisi tenaga kesehatan/praktisi medis/dokter di Indonesia cukup baik dikarenakan sinergi antara asosiasi profesi di bidang kedokteran dan pemerintah seperti Kementerian Kesehatan terjalin. Namun demikian, liberalisasi pelayanan kesehatan dan sektor medis pelu memeperhatikan dua hal berikut, yakni sektor kesehatan merupakan sektor penting yang terkait dengan keamanan negara dan sektor kesehatan perlu dilindungi dari sektor bisnis.

\section{Perawatan Gigi}

Praktisi perawatan gigi di Indonesia jika dibandingkan dengan negara-negara anggota ASEAN lainnya mengalami ketertinggalan. Hal ini dapat dilihat dari rasio dokter gigi per 10.000 penduduk. Indonesia memiliki rasio dokter gigi di bawah Myanmar. Indonesia berada dalam posisi yang sejajar dengan Laos 0,4 dokter gigi per 10.000 penduduk. Berikut adalah tabel penjelasan di atas:

Tabel 6. Angka Dokter Gigi per-10.000 Populasi

\begin{tabular}{|l|c|}
\hline \multicolumn{1}{|c|}{ Country } & $\begin{array}{c}\text { The Number of Dentists Per } \\
\text { 10,ooo Population }\end{array}$ \\
\hline Singapore & 3,3 \\
\hline Brunei Darussalam & 2,1 \\
\hline Malaysia & 1,4 \\
\hline Myanmar & 0,5 \\
\hline Indonesia & $\mathbf{0 , 4}$ \\
\hline Laos & 0,4 \\
\hline Cambodia & 0,2 \\
\hline Philipine & not available \\
\hline Thailand & not available \\
\hline Vietnam & not available \\
\hline
\end{tabular}

Sumber: World Trade Organization (WTO), 2013

Berdasarkan data di atas dapat dilihat bahwa dokter gigi memerlukan peningkatkan dari segi jumlah yang harus ditetapkan oleh pemerintah. Kualitas dokter gigi Indonesia agar dapat berkompetisi dengan negara lain, termasuk negara-negara anggota ASEAN memerlukan usaha yang sungguh-sungguh. Dari sisi pemerintah, kedokteran gigi perlu diperhatikan lebih serius. Karena karakteristik sektor ini, termasuk eksklusif dan terbatas 
yang dapat mengaksesnya. Kerjasama diantara institusi yang relevan dengan asosiasi profesional juga perlu diintensifkan agar terjadi hubungan saling menguntungkan untuk pengembangan sektor ini.

\section{Pariwisata}

Pariwisata merupakan salah satu sektor yang ditetapkan sebagai prioritas dalam liberalisasi sektor jasa ASEAN. Secara global, diperkirakan bahwa sektor pariwisata menyumbang sekitar 9\% dari PDB di seluruh dunia. Karena karakter yang khas, sektor ini merupakan sektor yang mampu menyerap tenaga kerja dari berbagai kalangan di masyarakat. Di negara-negara anggota ASEAN, pariwisata merupakan salah satu sektor yang berkembang sangat baik. Laporan the ASEAN Tourism and Travel Competitiveness yang diterbitkan oleh Forum Ekonomi Dunia memperkirakan bahwa kontribusi pariwisata terhadap PDB gabungan negara-negara ASEAN mencapai 4,6 persen. Dalam hal pekerjaan, sektor pariwisata diharapkan dapat secara langsung mempekerjakan sekitar 9,3 juta orang di seluruh ASEAN. Dalam persen, jumlah itu membentuk sekitar 3,2 persen dari total lapangan kerja. Secara tidak langsung, sektor ini juga berdampak pada 25 juta pekerjaan di negara-negara anggota ASEAN.

Salah satu isu penting dalam liberalisasi sektor jasa ASEAN adalah terbatasnya jumlah profesional pariwisata yang memiliki sertifikasi formal. Namun dari segi kualitas Indonesia sudah cukup baik dalam bidang ini. Keuntungan lain, dalam kaitannya dengan persaingan untuk pasar domestik di Indonesia terkait erat dengan atraksi wisata. Tentu saja masyarakat Indonesia secara alami memiliki pengetahuan yang lebih baik terhadap negara sendiri dibandingkan dengan negara-negara lain ASEAN. Tentu saja hal ini juga berlaku untuk pelaku industri pariwisata di masing-masing negara anggota ASEAN. Infrastruktur adalah masalah terbesar dalam pariwisata. Infrastruktur transportasi darat Indonesia masih jauh di belakang. Penting untuk diingat bahwa MRAs di bidang pariwisata mendorong mobilitas tenaga kerja terampil di bidang pariwisata, itu berarti, bahwa profesional pariwisata Indonesia dapat mengambil kesempatan untuk meningkatkan daya saing mereka jika mampu mengambil keuntungan dari infrastruktur pendukung pariwisata. Misalnya, membuka usaha pariwisata di Singapura adalah dan mengintegrasikannya dengan pariwisata Indonesia (misalnya paket ASEAN).

Sektor pariwisata ini memiliki keunggulan jika dibandingkan delapan profesi yang lain dalam masyarakat ekonomi ASEAN. Ketua Komite Tetap Sistem Sertifikasi Kompetensi SDM, Sumarna Abdurahman dikutip dari Tempo (2014) mengemukakan bahwa saat ini tenaga kerja sektor pariwisata sudah mempunyai Standar Kompetensi Kerja Nasional Indonesia (SKKNI), lembaga pendidikan, dan latihan serta Lembaga Sertifikasi Profesi. Walaupun demikian dikutip dari Suara Pembaruan (2014), Sumarna tetap mengkhawatirkan sektor pariwisata ini akan disesaki oleh tenaga kerja asal Thailand dikarenakan mereka sudah belajar bahasa Indonesia sekarang, sehingga jangan heran kalau pemandu di Bali nanti dari Thailand. 


\section{KESIMPULAN}

Berdasarkan pemaparan di atas, maka dapat disimpulkan bahwa Indonesia memiliki peluang dalam masyarakat ekonomi ASEAN. Statistik negara penempatan TKI menunjukkan bahwa Malaysia, Singapura, Brunei Darussalam dan Thailand telah menjadi negara tujuan. Jika dilihat dari paparan kondisi ketenagakerjaan Indonesia terhadap Mutual Recognition Agreements (MRAs) yang dipersyaratkan untuk kebebasan bergerak bagi 8 profesi dalam masyarakat ekonomi ASEAN, maka profesi di bidang pariwisata yang memiliki peluang untuk berkembang lebih pesat, hal ini didukung kesiapan sumber daya pendukung yang telah terintegrasi MRAs. Hal ini berarti TKI/PMI memiliki peluang untuk mengakses lapangan kerja yang telah disepakati bersama oleh negara anggota ASEAN melalui Mutual Recognition Agreements (MRA), namun demikian profesi yang telah disepakati MRAs masih membutuhkan dukungan untuk pengembangannya dari pemerintah Indonesia agar dapat dimanfaatkan secara optimal. Sedangkan tantangan bagi Indonesia dalam masyarakat ekonomi ASEAN yakni TKI/PMI yang masih didominasi oleh tenaga kerja informal/berketerampilan rendah, sehingga diperlukan upaya pemerintah Indonesia untuk meningkatkan minat sebagai tenaga kerja formal dengan melakukan inovasi pelayanan di bidang ketenagakerjaan, utamanya yang terkait dengan 8 profesi MRAs.

\section{BIBLIOGRAPHY}

Afriana, Linda dan Rishang Haryo Tutuko. (2015). Mapping and Role of Indonesian Skilled Workers and ASEAN Services Liberalization for Creating Strategic Value Different Sectors in the Mutual Recognition Agreement (MRA) Framework. Prosiding. International Conference on ASEAN Studies. Yogyakarta: ASEAN Studies Center Universitas Gadjah Mada.

Association of Southeast Asian Nations. (2011). Roadmap for an ASEAN Community 20092015. Jakarta: Sekretariat ASEAN.

Bank Indonesia. (2009). Laporan Survei Nasional Pola Remitansi TKI Tahun 2008. Jakarta: Bank Indonesia.

Caporaso, James A. dan David P. Levine. (2008). Teori-Teori Ekonomi Politik. Yogyakarta: Pustaka Pelajar.

Cipto, Bambang. (2007). Hubungan Internasional di Asia Tenggara: Teropong terhadap Dinamika, Realitas dan Masa Depan. Yogyakarta: Pustaka Pelajar.

Deliarnov. (2006). Ekonomi Politik. Jakarta: Penerbit Erlangga.

Dwi Yuwono, Ismantoro. (2011). Hak dan Kewajiban Hukum Tenaga Kerja Indonesia di Luar Negeri. Yogyakarta: Pustaka Yustisia.

Hoàng, Nguyen Huy. (2013). Toward an Integrated ASEAN Labor Market Prospects and Challenges for CLMV Countries. VNU Journal of Economics and Business Vol. 29, No. 5E (2013) 34-42. Retrieved from https://js.vnu.edu.vn/EAB/article/view/418.

Kementerian Luar Negeri. (2012). ASEAN Selayang Pandang. Jakarta: Direktorat Jenderal Kerjasama ASEAN Kementerian Luar Negeri.

Kementerian Tenaga Kerja dan Transmigrasi. (2011). Perkembangan Ketenagakerjaan di Indonesia. Jakarta: Kemenakertrans. 
Kotler, Philip dkk. (2011). Merebut Pasar ASEAN: Peluang dan Tantangan Bisnis di Asia Tenggara. Bandung: Kaifa.

Luhulima, CPF., dkk. (2008). Masyarakat Asia Tenggara Menuju Komunitas ASEAN 2015. Yogyakarta: Pustaka Pelajar.

Nugroho, Riant. (2014). Kebijakan Publik di Negara-negara Berkembang. Yogyakarta:

Pustaka Pelajar.

Orbeta Jr, Aniceto C. (2013). Enhancing Labor Mobility in ASEAN: Focus on Lower Skilled Workers. Discussion Paper Series. Filipina: Philippine Institute for Development Studies. Retrieved from https://www.econstor.eu/handle/10419/126934.

Streans, Jill dan Lloyd Pettiford. (2009). Hubungan Internasional: Perspektif dan Tema. Yogyakarta: Pustaka Pelajar

Suparman, Nuraeini, Deasy Silvya, dan Arfin Sudirman. (2010). Regionalisme dalam Studi Hubungan Internasional. Yogyakarta: Pustaka Pelajar.

Wailerdsak, Natenapha. (2013). Impacts of the ASEAN Economic Community on Labour Market and Human Resource Management in Thailand. South East Asia Journal of Contemporary Business, Economics and Law, Vol. 2, Issue 2 (June) 2013. Retrieved from http://seajbel.com/wp-content/uploads/2014/07/Impacts-of-the-ASEAN-Association-of-

South-East-Asian-Nations-Economic-Community-on-Labour-Market-and-Human-ResourceManagement-in-Thailand-Dr-Natenapha-Wailerdsak-Yabushita.pdf.

Zulfikar, Achmad. (2015). Mapping the Position of Indonesian Migrant Workers towards ASEAN Economic Community 2015. Makalah. Dipresentasikan pada $1^{\text {st }}$ International Conference of Journal Government and Politics di Universitas Muhammadiyah Yogyakarta, 14 Maret 2015. Retrieved from https://dx.doi.org/10.17605/OSF.IO/5CEFW.

\section{Internet}

Kementerian Ketenagakerjaan. (2014). Hadapi MEA 2015 Pemerintah Fokus Siapkan 8 Profesi Prioritas. http://ppid.depnakertrans.go.id/hadapi-mea-2015-pemerintah-fokussiapkan-8-profesi-prioritas. Diakses 1 November 2016.

Tempo. (2014). Hanya Tenaga Kerja Ini yang Siap di Pasar Bebas?. http://www.tempo.co/read/news/2014/05/02/090574773/Hanya-Tenaga-Kerja-Ini-yang-Siapdi-Pasar-Bebas. Diakses 2 November 2016.

Pikiran Rakyat. (2016). Di Era MEA TKA Tak Bisa Dibendung. http://www.pikiranrakyat.com/ekonomi/2016/01/21/358010/di-era-mea-tka-tak-bisa-dibendung. Diakses 5 November 2016.

Suara Pembaruan. (2014). Indonesia Terancam Jadi Pasar Tenaga Kerja ASEAN. http://sp.beritasatu.com/home/indonesia-terancam-jadi-pasar-tenaga-kerja-asean/54233.

Diakses 7 November 2016. 